\title{
El arte de la conversación literaria: su concepto y metodología para fomentar la competencia literaria y comunicación'
}

\author{
The Art of Literary Conversation: Its Concept and Methodology \\ in Order to Promote Literary Competence and Communication
}

\author{
ISABELLA LEIBRANDT \\ Universidad de Navarra \\ España \\ ileibrandt@unav.es
}

(Recibido: I6-O3-20I7; aceptado: $07-09-2017)$

Resumen. Este artículo presenta a la vez un marco teórico sobre el concepto de la conversación literaria y describe también algunos procedimientos útiles para su dirección en el aula, aplicables tanto a alumnos de LI como L2. Partimos de la presuposición de que el objetivo central de la enseñanza de la literatura es la comprensión textual entendida como la capacidad de emplear textos literarios para poder usarlos con una nueva visión de la realidad. Para ello, es necesario que los alumnos lleguen a la comprensión textual de un modo adecuado y al mismo tiempo individual. En adelante trataremos el modelo de Heidelberg de la 'conversación literaria' como un acceso a la comprensión del texto, que sitúa a todo docente ante la cuestión fundamental: ¿Qué es exactamente lo que deben hacer los estudiantes para comprender los textos literarios de forma más productiva? A continuación describiremos una serie de experiencias con más precisión.

Palabras clave: didáctica; literatura; lectura; competencia literaria.
Abstract. This paper presents the theoretical concept of literary conversation and also describes some useful procedures for its implementation in the classroom, both with $\mathrm{LI}$ and $\mathrm{L} 2$ learners. The assumption is that the core objective of literature teaching is to develop reading comprehension skills, understood as the ability to apply literary texts to a new vision of reality. It is therefore necessary for students to reach textual understanding in an appropriate manner as well as individually. Thus, we present the Heidelberg model of 'literary conversation' as an access to literary understanding that raises the fundamental question for every teacher: What is it exactly that students should do to understand literary texts in the most productive way? In this article we describe some examples more precisely.

Keywords: Didactics, Literature, Reading, Literary Skills

\footnotetext{
${ }^{\text {I }}$ Para citar este artículo: Leibrandt, Isabella (2018). El arte de la conversación literaria: su concepto y metodología para fomentar la competencia literaria y comunicación. Alabe 17 . [www.revistaalabe.com]

DOI: IO.I5645/Alabe2OI8.I7.8
} 
Los textos literarios hacen posible que los lectores desarrollen experiencias que pueden ser de gran importancia para su desarrollo personal e interacción con la sociedad.

(Saupe, 20I2: 28)

\section{El concepto de la conversación literaria según el modelo de Heidelberg}

Con el término específico de 'conversación literaria' queremos presentar una determinada metodología como parte central de las clases de literatura que, a la vez abarca múltiples competencias involucradas, entre otras la competencia lectora, la competencia para conversar, argumentar, escuchar y entender en cuyo transcurso influyen además factores emocionales y motivantes. No queremos ocultar el hecho de que la conversación literaria implica una ambigüedad inherente, que marca toda la comunicación estética frente a otras conversaciones lectivas.

Es que, a la dificultad de conseguir un resultado satisfactorio, se añade aquella de que no hay unos objetivos claramente predefinidos de modo previo, sino que el contenido de la conversación va tomando una forma u otra durante su desarrollo y las contribuciones de los participantes. Para dar a conocer el método y sus características, compartimos aquí las consideraciones sobre la conversación en el aula de literatura formuladas por Zabaka (20I5: I69):

La conversación en las clases de literatura es, en parte una forma de adquisición de competencias de conversación, y por el otro, un medio para la adquisición de ciertas competencias literarias. Como forma de aprendizaje de la conversación no sólo capacita para la participación en el discurso sobre objetos estéticos, sino que también para la participación en el discurso sobre asuntos sociales, morales y políticos. Como medio del aprendizaje literario, la conversación es especialmente adecuada para la formación de la competencia del juicio estético, entendida como la competencia de la interpretación y valoración. Debido a que la competencia de la conversación y las competencias literarias primero deben ser adquiridas en la conversación del aula la dirección de la conversación todavía se encuentra ante el cometido metodológico de establecer impulsos para la conversación - comparable a las tareas de aprendizaje - de forma que promuevan la comprensión y comunicación. Tanto una dirección demasiado constreñida, como una apertura en exceso pueden impedir el aprendizaje. Por tanto, es necesario que los docentes dispongan de un repertorio de impulsos para la conversación y de categorías para la evaluación situacional de su idoneidad para el aprendizaje².

\footnotetext{
${ }^{2}$ Todas las citas son traducciones del original por la autora.
} 
En adelante me dedicaré a ahondar en las dificultades mencionadas por Zabka, la dirección de la conversación, así como el establecimiento de los así llamados 'impulsos', para concretizar este tipo de metodología, que intento aplicar y adaptar según las necesidades y exigencias de los participantes en los cursos de conversación en los cuales profundizamos en la lengua y cultura alemana a través de lecturas de narrativas literarias. En primer lugar haré referencia al proyecto muy conocido en los países de habla alemana bajo el nombre del 'modelo de la conversación literaria de Heidelberg'. Con ello espero contribuir sobre todo un enfoque teórico complementario a los investigadores y docentes hispanoparlantes interesados en las 'lecturas dialógicas' como concepción de aprendizaje de la lectura y escritura y quienes en los últimos años también han difundido sus experiencias con este método tanto en la Educación Primaria como Secundaria demostrando que se trata de una metodología flexible y adaptable a diferentes edades y niveles educativos si se toman en consideración determinados fundamentos teóricos (Valls, Soler y Flecha, 2008; Álvarez, Gónzales y Arrinaga, 20I2; Pulido y Zepa, 2OIO; Martín y Jiménez, 20I3; García-Carrión, Martinez de la Hidalga y Villardón, 20I6).

En Alemania se trata de una investigación del campo de la didáctica de la literatura iniciada alrededor del año 2000 en la Universidad de Heidelberg donde profesores y estudiantes, en función del aprendizaje a través de la investigación y por medio de proyectos, exploraron las posibilidades de la comprensión literaria a través de la conversación. Con este fin se investigaron los fundamentos teórico-literarios y de comprensión, y se exploraron también las formas prácticas de la conversación aplicadas a textos literarios complejos, especialmente la poesía y la prosa corta. Los defensores de este método parten de la presuposición de que la conversación abierta y auténtica, culturalmente muy enraizada en los países de habla alemana, fuese la más apropiada para la enseñanza de la literatura. La comprensión literaria, entendida como un proceso de conversación en el que todos los participantes intervienen por igual, se basa a su vez en una posición intermedia entre la hermenéutica y la teoría textual deconstructivista.

Dada la creciente resonancia que está recibiendo el 'modelo de Heidelberg de la conversación literaria', principalmente en Alemania, quiero, dar a conocer esta metodología que intenta hacer frente a las tendencias didácticas de la literatura predominantes, y que consisten todavía frecuentemente en procedimientos interrogativos y lectivos. La conversación literaria, en cambio, quiere ofrecer un concepto que intenta hacer mejor justicia al texto, a su comprensión y a los participantes como un grupo interactivo. Con este presupuesto importante a la vista me centro más bien en la función de los enseñantes dado que nos encontramos con una de las consecuencias prácticas, identificar cuál es nuestro rol en este tipo de acercamiento a la literatura. Nos obliga, por tanto, primero a familiarizarnos con ciertos métodos para que no actuemos simplemente como moderadores, sino que nos incorporemos a la conversación literaria en el aula con nuestras propias contribuciones, expresando incluso nuestra propia incomprensión en la búsqueda común del significado. En otras palabras, en las propuestas de los defensores de este método encontramos el requisito importante que persevera en actuar como 'otro com- 
petente’ más en el proceso de la comprensión y, al mismo tiempo, como participante en el infinito camino de la nunca concluyente comprensión. Como sabremos todos los que enseñamos es precisamente nuestra implicación y disposición a cambiar la metodología el punto determinante para buscar un aprendizaje exitoso a la vez que superar las dificultades que se nos plantean y que esta metodología también contiene. Así lo especifica Bittner (2006: 8):

Entre todas las consideraciones y procedimientos didácticos que tenga el educador a su disposición, la conversación es uno de los métodos más difíciles. Requiere un buen oído, experiencia práctica y una gran cantidad de conocimientos sobre los procesos interpersonales con el fin de distinguir una conversación exitosa de un intercambio de palabras ineficaz.

A pesar de ser uno de los métodos más difíciles, señalamos que la conversación literaria se ha puesto en práctica en la enseñanza de todos los tipos y edades escolares y ha obtenido una amplia recepción en el discurso didáctico sobre la literatura alemana. La teoría y ejemplos prácticos han sido ampliamente documentados en la bibliografía reciente alemana (Bittner, 20o6; Härle y Rank, 2004; Härle y Steinbrenner, 20I4; Steinbrenner, Mayer y Rank, 2OII y Zabka, 20I5) a la que haremos referencia para proporcionar una visión general y establecer conexiones con la teoría, sin omitir sus dificultades y nuevos retos para la enseñanza de la literatura.

Nos acercamos primero a las semejanzas y diferencias en la conversación de la vida cotidiana y aquella del entorno educativo. ¿Cuáles son, por tanto, los rasgos específicos de la conversación en el aula? Para Härle (2004: 138) toda nuestra experiencia radica en la conversación; sin conversar, la experiencia literaria es impensable, dado que la literatura se escribe con la intención de conversar sobre ella. Pero no todo discurso es una conversación, como la entienden los autores mencionados. Para que el mero acto de hablar pueda considerarse como una conversación se requiere de una cierta intencionalidad y nivel. En este sentido, Valls, Soler y Flecha (2008) destacan el diálogo igualitario y del debate para aumentar la motivación y curiosidad para aprender de los demás al compartir el conocimiento a través de la indagación e interacción dialógica.

Es por tanto necesario insistir que la conversación literaria debe perseguir unos objetivos que coinciden con la calidad de una 'verdadera conversación'. La conversación literaria debe permitir un proceso interactivo de comprensión, en el sentido de una búsqueda común del significado debido a que el texto literario escapa, en algunas ocasiones, a la comprensión inmediata y, por lo tanto, a la interpretación inequívoca: "En otras palabras: el que se involucra en la literatura en su verdadera dimensión, se involucra en el problema de la comprensión y la implícita no-comprensión” (Härle, 2004: ı46).

Nos apoyamos en Härle y Steinbrenner (200I4: I6) al ver la necesidad imprescindible de definir bien el concepto de la conversación, dado que, bajo este término, se entienden formas y eventos comunicativos bastante divergentes. La gama de usos del término se extiende desde una definición puramente descriptiva, en el sentido de una charla en común (Pulido y Zepa, 2OIO: 3O2), hasta concebir la conversación en forma de una 
comunicación comunitaria de un movimiento espiritual, emocional y personal (Martín y Jiménez, 2OI3: 5-6). Es cierto que para una exitosa conversación en cualquier entorno educativo, ante todo es importante crear un ambiente de cercanía y confianza siendo sobre todo esencial para la planificación, ejecución y reflexión en la enseñanza de la literatura. Destaco en este marco pedagógico un concepto de la conversación entendido principalmente como un método de solución de problemas en común, y no como la evocación de respuestas a preguntas concretas.

Partiendo de estas cuestiones, nos referimos a Steinbrenner y Wiprächtiger-Geppert (2OIO) quienes, además, presentan la conversación como un monólogo interior con un texto y con un interlocutor real. Se trata, por tanto, de percibir la comprensión en su proceso dinámico, que es básicamente lingüístico, una forma individual y en última instancia infinito: "no hay una última palabra". A este tipo de una interpretación dialógica en la cual no existe una única interpretación experta hacen referencia Pulido y Zepa (2OIO: 297) citando a Bakhtin quien a su vez se pronuncia a favor de un diálogo intercultural como enriquecimiento mutuo. En este sentido, la dialogicidad y el carácter del proceso de una conversación pueden permitir diferentes interpretaciones y una interacción dinámica entre el texto y las personas. La conversación real se alimenta sobre todo del encuentro directo afectivo y personal. Puede enriquecerse por el lenguaje específico de los textos literarios. Bajo estas premisas, fue diseñado y probado un modelo de conversación en el marco del proyecto de investigación que no busca unas interpretaciones cerradas, sino que permite el desarrollo del significado del texto en el proceso de la conversación.

Siguiendo estas líneas de argumentación, señalamos que el 'modelo de Heidelberg' no es tanto una técnica específica, sino más bien una determinada actitud frente a los participantes, el texto y la conversación, pero que puede formularse bajo ciertas líneas metodológicas. De ahí sostenemos que es necesaria una cierta competencia personal y profesional que no puede presuponerse, sino que debe ser transmitida en la formación del profesorado. Dada la apertura del método y ciertas controversias que cuestionan si estos modos metodológicos realmente son conversaciones reales, y si los participantes pueden aprender algo con ellas, los autores citados definen algunos conceptos útiles para la planificación, dirección y evaluación de las conversaciones en el aula de literatura en forma de propuestas y en un marco general de la conversación en el aula, así como un desarrollo en diferentes fases. Al exponer los fundamentos acerca de la conversación literaria en el aula, queremos a la vez articular algunos dilemas relacionados con su dirección. Con estas premisas seguimos a Härle (20II: 48-54), quien, entre otros, analiza el rol del enseñante como moderador, y sus cualidades de 'compañero de aprendizaje', cuya función, por tanto, se diferencia significativamente del docente tradicional, como explica, más concretamente, en la siguiente afirmación (Härle, 2OII: 48):

En la conversación literaria se realiza en forma de una dirección participativa una mediación dialéctica de silencio y participación, rol funcional y participación personal, preceder, acompañar y seguir. La capacidad de un guía para la dirección participativa es una competencia que debe ser aprendida. 
Otras tareas precisas del enseñante, señaladas por el autor y a las que dedicaremos otro apartado, son la necesaria preparación de la conversación literaria que requiere la selección adecuada del texto, el trabajo intelectual con él, el desarrollo del tema, el perfilar del desarrollo de la conversación, así como la programación de los así llamados 'impulsos'.

\section{Interlocutor - moderador - enseñante: nuevos roles y funciones}

En la concepción de esta metodología no queremos pasar por alto una de las partes involucradas, que es el docente. Pulido y Zepa (20I0: 299), mencionan al respecto ciertas responsabilidades del moderador relativo a la interacción con los participantes y ofrecen un ejemplo de una tertulia. En un entorno más académico dependiendo de la edad y del interés de los estudiantes el método puede causar problemas cuando los alumnos no muestran una actitud positiva o no hayan leído con suficiente atención los correspondientes capítulos como bien describen Martín y Jiménez (2OI3: 8). Posiblemente ocurra entonces que la conversación sea muy superficial y los comentarios poco relevantes.

Al igual que Bittner (2006: 15), por tanto, destacamos como norma máxima de la conversación, la capacidad del individuo, sea moderador o participante en la conversación, de interesarse por cosas nuevas y desconocidas que, en este caso significa, por ejemplo, dejarse llevar por un comentario en la conversación para entrar en un nuevo tema. Con esta apertura a 'expediciones a terrenos desconocidos', el participante en la conversación muestra al mismo tiempo su principal disposición para aprender algo nuevo. La conversación literaria es una forma de diálogo muy exigente por ambas partes y requiere, por tanto, por parte de sus participantes una capacidad de atracción hacia nuevos y desconocidos temas, y al mismo tiempo debe saber percibir las peculiaridades personales de los demás participantes.

En relación con esto, mencionamos la empatía en un doble sentido, y como un requisito indispensable para la comprensión mutua y textual. Significa dar inicio a un encuentro personal y empático con los alumnos y con un texto literario. En este contexto se aplica el término de la 'autenticidad', concebido por Bittner en el sentido de estar abierto a las emociones o los sentimientos, aceptarlos en consonancia con los valores de la apertura, flexibilidad y tolerancia, y aprovechar la oportunidad para compartir su propia experiencia con los demás.

En esta concepción observamos una importante relación entre los rasgos de la personalidad de todos los participantes y los aspectos importantes relacionados con el aprendizaje de la literatura, la imaginación y la creatividad, el auto-conocimiento y la comprensión del otro, al igual que la disposición para enfrentarse a preguntas humanas básicas, así como la voluntad para comprometerse emocionalmente con el texto y participar subjetivamente en la conversación. Mencionamos en particular, esta capacidad de percepción para el moderador que es primordial a todos los niveles, dado que exige per- 
cibir los puntos de vista de las figuras literarias y de los participantes, incluso si no coinciden con las normas vigentes del lector-participante. De este modo puede establecerse una relación recíproca muy fructífera para ambas partes. Por un lado, el lector enriquece el texto con su experiencia vivida, por otro lado, el texto literario enriquece a sus lectores a través de momentos estéticos, los cuales en el caso de que falten a su experiencia cotidiana, requerirán por tanto un mayor esfuerzo de comprensión. La conversación literaria amplía, por tanto, la comunicación literaria con el encuentro de otras lectoras y lectores. Resaltamos que esta calidad, sin embargo, no es algo gratuito, sino un objetivo al que se aspira con cada nuevo encuentro con la literatura en la comunicación literaria.

Para que la comunicación literaria tenga calidad respecto de su contenido que es la literatura y no se derrame por anécdotas personales y triviales me decanto por seguir a Spinner (2004: I69-I73), al destacar en este complejo proceso de la comprensión, sobre todo, las dimensiones de la imaginación, empatía y subjetividad para la comprensión literaria. En primer lugar, nos percatamos como docentes de que para lograr una estimulante conversación literaria, debemos saber despertar la imaginación en los alumnos, que es un requisito previo para la comprensión literaria, y por otro lado, la lectura promueve la capacidad de imaginar. Cuanto mayor esté desarrollada la capacidad de la imaginación, tanto más fructífera será la identificación empática con las figuras literarias, con diferentes situaciones extrañas de la vida y la capacidad de saber comprender los pensamientos y sentimientos de los personajes. Es, por tanto, una de las competencias esenciales que requiere la lectura literaria, pero no se debe dar por hecho que el lector se imagine algo. Con frecuencia es necesario estimular la imaginación a través de impulsos visuales o de otro tipo, auditivos, olfativos, táctiles, que sirven principalmente para la interpretación. La implicación emocional en el texto incluye, por ejemplo, la experiencia de lo cómico, del suspense, del miedo, del terror, de la compasión o la empatía. En particular, la empatía puede ser un requisito clave para la comprensión textual. En contraste con la identificación se entiende la empatía como una compasión desde la perspectiva de un observador, que también permite un distanciamiento.

Con Spinner (2004), además, llamo la atención sobre la importancia de la subjetividad en la comprensión literaria que va más allá de la recepción. Con este concepto, el autor se refiere al proceso de la auto-comprensión en la lectura literaria; en otras palabras, el enfrentamiento a sus propios deseos, la tristeza, la rabia o los conflictos morales que se generan en la lectura. Esta vinculación del texto literario con la experiencia personal se articula en una interacción entre la comprensión textual y la auto-reflexión subjetiva. Al reincidir hasta aquí en las capacidades de la imaginación, empatía, subjetividad y autocomprensión, deseo hacer ver la importante implicación personal para la comunicación literaria que, por tanto, se expresa en un espíritu de valentía a diferentes niveles. NickelBacon (2OII: 134) lo formula de la siguiente manera: "se trata de percibir dónde y de qué modo el texto llega profundamente a mi propio ser y, en segundo lugar, tener la valentía para compartirlo con los demás". 
Comparto con la autora esta idea y el requisito necesario de la valentía como principal disposición para saber expresar y aceptar ambivalencias, irritaciones o el placer durante la lectura, entendidos como una oportunidad para experimentarlos en relación con la literatura que, a su vez, permite adoptar una posición de interés como forma de vivencia. Frecuentemente es notable al mismo tiempo que, en especial los alumnos con experiencias anteriores demasiado dirigidas en el aula de la literatura hacia una determinada comprensión literaria, necesitan familiarizarse y ser animados a ser sinceros en los comentarios emocionales y cognitivos, como sucede también con los propios enseñantes, si quieren transmitir una visión más personal del texto o del mundo relacionado. Con ello incidimos a la vez en la requerida competencia de comunicación que se plasma en el modo de saber negociar posibilidades de significados, buscar palabras adecuadas y tener el valor de expresarlas. De ahí que respaldamos la metodología de la conversación literaria de sus principales representantes Härle y Rank (2004: 5), quienes postulan que es necesario permitir que los participantes experimenten con textos literarios, pues requieren "de un acercamiento paulatino, paciente e incluso detectivesco que debe incluir incluso lo extraño, la incomprensión y el rechazo", y no tratar estas competencias como materias que puedan ser adquiridas a través de determinadas operaciones.

En conexión con los requisitos particulares de la conversación literaria señalamos que, en primer lugar, el docente mismo debe disponer de un serio interés de unirse a los estudiantes en la conversación sobre el texto seleccionado, tanto en sus impresiones receptivas como interpretativas, y estar dispuesto a contribuir con las propias impresiones de forma adecuada. Con la selección personal del texto, el docente muestra sentirse atraído por él, y en consecuencia indica que los temas y el lenguaje del texto son suficientemente adecuados para estimular la conversación de los participantes. Podemos corroborar que se ofrecen todos aquellos textos con cierta apertura, dado que no transmiten simplemente un mensaje, sino que proporcionan un incentivo para la conversación por su ambigüedad, el misterio y su configuración lingüística inusual. Lo último es especialmente importante para que la conversación gire sobre el texto y su lenguaje, y no sólo sobre las cuestiones planteadas por él (Steinbrenner y Wiprächtiger-Geppert, 20IO). Especialmente fructífera para la interacción literaria en nuestro grupo de conversación se ha revelado la novela postmoderna debido a sus rasgos que son la intertextualidad, el juego, la apertura, las biografías ficcionales y el rol intencional del lector.

Con los mencionados requisitos de una conversación literaria lograda quiero hacer hincapié en la implicación personal que se refiere a la capacidad de cada uno para abrirse y sentirse personalmente llamado, lo cual Zabka (2OI5) entiende por un 'auto-conocimiento ampliado’. Para este pedagogo, la combinación entre la implicación personal y una percepción textual exacta entraña un ideal que debería ser alcanzado en las ciencias literarias. La conversación como método en sus diferentes formas en la clase de la literatura, según el autor, debe hacer justicia sobre todo a la competencia del interpretar, entendida como la ‘no concluyente formación del significado’ sin restringir la ambigüedad. 
Con esta principal controversia de la implicación personal y percepción textual exacta a la vez reflejo brevemente una muy debatida cuestión que ha ocupado a los expertos en didáctica alemanes a lo largo de los últimos años. Las posiciones de Zabka, Spinner y otros rechazan tajantemente aquellas formas de conversación en las cuales se impide una pluralidad de la interpretación abierta que en vez de garantizar un 'movimiento de búsqueda' al interpretar, favorecen una búsqueda restringida para obtener una comprensión correcta. En esta forma errónea de la conversación del tipo de “interpretación interrogativa', los autores critican que la intención de guiar a los estudiantes hacia un pensamiento independiente fracasa y, por tanto, se convierte en lo contrario, a saber, en un obstáculo para el auto-pensamiento. En segundo lugar, los autores realizan un llamamiento para evitar aquellas formas de conversación en las cuales se perturba el 'equilibrio entre la autodeclaración, el tomar en serio al otro y la referencia textual'. Con ello hacen referencia a tales deformaciones que se producen cuando los participantes expresan sus impresiones sobre la lectura de forma yuxtapuesta sin referirse uno al otro; o bien cuando, al hablar sobre sus propias emociones, ideas y pensamientos, se independiza respecto al texto y éstos son la única razón de la conversación, pero no su tema; o si por el contrario, el hablar exclusivo o principal sobre el texto y los potenciales del significado histórico, llevan a que la articulación de las impresiones de lectura e interpretaciones personales se marginen o repriman.

Como he mencionado anteriormente, para una conversación literaria exitosa, he comprobado que, aparte de las competencias didácticas del enseñante y la colaboración necesaria de los participantes, juega un papel fundamental la posibilidad de poder seleccionar el texto en función de las características de los alumnos. Con este argumento se expresa cierta crítica hacia un canon impuesto o demasiado rígido sin opciones de elección. En este sentido, Zabka (20I5) reclama acertadamente un repertorio de textos que permiten fortalecer la cohesión de un grupo social por razones subjetivas de cada uno de los participantes, quienes así pueden aportar algo a un intercambio comunicativo. En este sentido, para el éxito de la conversación en el aula destaca la condición predominante de saber crear y hacer prosperar una cultura positiva de diálogo como el centro de la clase. Es un aspecto que afecta al rol del moderador y a la competencia comunicativa clave dado que requiere encontrar un equilibrio entre la libertad y la necesaria dirección. Destaco, según Werner (20I4: 2I6), las siguientes facetas que debe dominar un moderador: organizar la relación interactiva, cuidar en la conversación el cumplimiento de expresiones de razonamiento por todos los participantes, enlazar los argumentos de los hablantes, recoger los cambios en el razonamiento por parte del grupo y utilizarlos posteriormente en la conversación, resumir al final los comentarios y las interpretaciones.

Por otro lado, los enseñantes también debemos saber conseguir que los participantes descubran las cualidades literarias de los textos de ficción y, gradualmente, aprendan a reconocer dónde se encuentra su valor. Los autores aquí citados defienden el postulado de que estos procesos tengan lugar en el caso ideal, sin ningún 'impulso’ o intervención por parte del docente, que sean los estudiantes quienes conduzcan las conver- 
saciones, se motiven a sí mismos para determinadas articulaciones de la comprensión y hagan referencia a otros participantes, que adquieran la habilidad necesaria para responder a las contribuciones del otro con preguntas y comentarios, de modo que ellos mismos brindan los así llamados ‘impulsos de conversación’. De este modo, deberían aprender a conversar juntos, y no como suele ser el caso, dirigirse solamente hacia el enseñante. En el transcurso de tales procesos los participantes en la conversación también adquieren experiencia sobre la incomprensión, confusión y la extrañeza. El saber articular, soportar y considerarlas una parte del proceso de la comprensión exige unas habilidades y actitudes necesarias que han de ser adquiridas en la conversación literaria. Implica, además, el fomento de la tolerancia a la ambigüedad, para que los participantes desarrollen un sentido para la inmensidad del proceso de la comprensión literaria.

\section{La dirección de la conversación literaria: los impulsos}

Sin descartar del todo cierta incertidumbre del método hacia el resultado deseado, me pongo del lado de los que consideran que la conversación literaria fomenta particularmente bien estas dos funciones: como medio de aprendizaje impulsa las competencias parciales (a) de la recepción literaria y (b) de la formación lingüística. Al promover la capacidad de la conversación sobre textos estético-ficcionales, prepara a los participantes para una conversación sobre el arte y la literatura en general. Sin embargo, en lo dicho hasta aquí he observado que la conversación literaria como método en el aula se enfrenta a un dilema que podemos formular de este modo: ¿cómo se puede conversar en el aula acerca de los fenómenos estéticos, de manera que la experiencia estética no se agote en un mero parloteo, sino que pueda ser profunda y ser satisfactoria para todos los participantes?

No dudamos de que toda conversación libre requiera cierta dirección por parte del docente en la medida que sea esencial. En adelante queremos detenernos en (posibles) modos de dirección de la conversación, para la cual pueden formularse ciertas directrices metodológicas, a pesar de que no se trata de técnicas específicas que garanticen un aprendizaje exitoso, sino más bien de una determinada actitud frente a los participantes, al texto y a la misma conversación. Para evitar el procedimiento habitual interrogativo - 'no apto para la comprensión de textos' - que lleva a los participantes a una interpretación pre-determinada, la conversación puede (y a menudo requiere ser) promovida por el docente mediante ciertos 'impulsos', por ejemplo, para estimular la reflexión. Con los 'impulsos de la conversación', método clave, nos adentramos en la dificultad y el arte de dirigir adecuadamente una conversación cuyo espíritu Zabka (20I5: I85) formula de la siguiente manera:

Iniciar un entendimiento sobre la comprensión de textos literarios y mantenerlo vivo, sin impedir la reflexión independiente de los estudiantes por unos impulsos de dirección demasiado abiertos o demasiado cerrados, es un arte que en cada caso deben probarse, 
cuyas técnicas pueden sistematizarse y aprenderse, y cuya idea reguladora es hacerse superfluo a uno mismo. El arte de la conversación va dirigido siempre hacia la habilidad de los estudiantes para dirigir las interpretaciones o una conversación elaborada sin el apoyo del docente.

Respecto al aprender el 'arte de la conversación’, consideramos tanto más importante la función de la didáctica de la literatura para ofrecer un 'repertorio de posibles y necesarios impulsos' aunque, como advierte el autor, estos no se dejan siempre planificar como unas tareas antes de la clase. Más bien requieren decisiones adaptativas ad hoc en relación con las contribuciones de comprensión que no siempre son predecibles. En su diferenciación funcional, Zabka (20I5: I76) propone elaborar los siguientes impulsos tanto para una selección del texto como para activar y provocar respuestas, ideas y reflexiones en los participantes:

- He elegido este texto (motivos personales/hechos) porque...

- Los puntos sobre los que los participantes podrían conversar...

- Impulsos para la primera fase...

- Impulsos que conducen más bien al texto...

- Impulsos que conducen más a las experiencias propias...

- Impulsos para la fase final...

A continuación ofrecemos un repertorio de propuestas en términos generales de varios autores (Zabka, 2OI5; Saupe, 2012 y Härle, 2OII), dado que, en la práctica, las fases y los métodos de la enseñanza dependerán de cada proceso concreto. Distinguimos en función de las diferentes fases durante la conversación 'impulsos' de inicio, dirección y reflexión. Los impulsos de iniciación son pensados para crear una resonancia con la lectura y están destinados a alentar aquellas reacciones internas (afectivas, asociativas y cognitivas) que han surgido a lo largo de la lectura. Estos impulsos, aparte de tener una función directiva, ofrecen diferentes recursos en el enfoque hacia el texto, por ejemplo, una línea, una expresión, una parte que me ha llamado especialmente la atención, irritado, dejado confuso o creado resonancias internas en los participantes, al provocar imágenes, sentimientos o estados de ánimo desencadenados por el texto (Härle, 2OII: 54).

Concebimos los impulsos de iniciación como pasos que fomentan las operaciones de comprensión y su articulación, de modo similar a las estrategias de lectura que están pensadas para un determinado modo de acercarnos al texto. Serán especialmente necesarios cuando escaseen las aportaciones de los estudiantes, para iniciar una conversación o estimular una primera comprensión del texto, es decir, al principio de la conversación, o cada vez que la conversación no siga adelante (Zabka, 20I5: I83-I84 y Steinbrenner y Wiprächtiger-Geppert, 20IO).

Una primera fase decisiva en la dirección de la conversación hacia la comprensión del texto incluye la presentación del texto mismo con el fin de preparar y estimular a los participantes para la lectura del texto, el cual precisa una forma lo más motivadora posible, por ejemplo: a través de asociaciones de imágenes, citas y párrafos. No menos importante será una activación o aportación del conocimiento específico necesario para 
la comprensión como fechas, eventos o personajes históricos, lugares, nombres. Como forma de provocar asociaciones puede resultar útil buscar vínculos o comparaciones sobre el tema (amor, viaje, huida, conflictos generacionales etc.) con películas, otras novelas o canciones que conocerán los participantes.

A esta fase del primer contacto previo a la lectura con el libro, autor o la época que consiste en despertar interés para la lectura, descubrir algo nuevo y desconocido, a la vez que permite conectar con el mundo individual de cada participante, seguirá la fase de lectura libre o guiada, según los propósitos, la edad y el nivel de conocimientos del idioma de los participantes. La interpretación de la obra literaria posiblemente debe complementarse con conocimientos sobre su lenguaje y mundo. En algunos casos también pueden además incluirse conocimientos genéricos o históricos, si es necesario. Notamos que muchos simplemente leen el texto en cuanto a su acción, lo cual exige llamar la atención sobre estructuras, expresiones, juegos de palabras, imágenes o metáforas como condición necesaria para una interpretación textual adecuada. Posibles instrucciones pueden ser:

- elaborar notas al margen;

- formular comentarios y preguntas, comparaciones y valoraciones;

- ¿a qué me recuerda la historia?, ¿qué otro suceso se me ocurre con un fin similar?, ¿me gusta cómo termina la historia?, ¿qué pienso acerca de la actuación de los personajes?;

- formular una primera comprensión en una conversación entre dos.

Impulsos dirigidos hacia suposiciones sobre los motivos de la actuación, hacia una evaluación de los modos del comportamiento o hacia una contextualización, la historización o actualización:

- expresar las razones que tienen las figuras para actuar de esta forma: ¿qué opinas de la actuación del personaje?, ¿cómo actuarías en una situación similar de la vida?

Señalamos una destacada función de estos impulsos de iniciación para la apropiación subjetiva de lo leído. El enseñante y los participantes pueden aportar sus contribuciones, en las cuales su formulación permite una referencia personal al texto. En este sentido, un buen y estimulante impulso crea, en caso ideal, una conexión entre el texto y los participantes en la conversación, impulsa sobre todo la conversación si ofrece una estructura dialéctica. Toda conversación en el aula guiada por lo general, comienza con un impulso abierto, por ejemplo con preguntas como:

¿Qué párrafo te hallamado particularmente la atención o te ha irritado? ¿qué

os pareció...?, ¿qué pensáis acerca de...?, ¿qué os ha llamado la atención?

Dado que el objetivo de la conversación literaria no es una interpretación estricta, sino la búsqueda común de posibles significados, no necesariamente deberá haber un producto final, aunque por supuesto pueden incluirse exposiciones orales o entradas escritas en un bloc de curso. En este sentido, es decisivo para el desarrollo de la conversación experimentar con diferentes posibilidades de significado en una labor conjunta 
sobre el texto. Para ello Zabka (20I5: I83-I84) ha elaborado la siguiente lista de impulsos importantes que, en la columna de la derecha, se leen como proto-formulaciones, y en relación con el texto relevante y la situación pueden formularse de modo más concreto, estimulante, personal y no solo como preguntas.

\begin{tabular}{|l|l|}
\hline Impulso: & Ejemplo: \\
& ¿Cómo has entendido este pasaje? \\
repetir & ¿Qué hay de nuevo en esta idea? \\
acentuar & ¿Qué justifica ahora esta interpretación? \\
resumir & ¿Hay algo en contra de esta interpretación? \\
problematizar & ¿Por qué os convence esta interpretación? \\
evaluar & ¿Cuáles son las implicaciones para los otros párrafos? \\
continuar & ¿Se pueden conectar las declaraciones de Ay B? \\
realizar conexiones & ¿Aqué párrafo/ tu propia experiencia te refieres? \\
fundamentar & ¿Qué se entiende mejor con tu interpretación? \\
explicar & ¿Cómo lo puedes justificar con el texto o con tu propia \\
justificar & experiencia? \\
\hline
\end{tabular}

El docente a continuación moderará la conversación, animando a expresar diferentes aportaciones por parte de los participantes, resume lo dicho terminando con la formulación de posibles cuestiones pendientes. Evidentemente en este procedimiento jugamos con la calidad de las aportaciones de los participantes, que son un factor clave para el éxito de la conversación, dado que cuanto mejor están desarrolladas las competencias comunicativas de los alumnos en relación con la comprensión del texto literario, tanto más el moderador se puede limitar a una mera moderación. En esta función puede señalar las contribuciones particularmente interesantes o problemáticas para que el grupo exprese sus opiniones.

En esta fase de la conversación, las experiencias personales, al igual que sus propias ideas, pueden ser un enriquecimiento para todos. Los estudiantes deberían ser capaces de desarrollar una interpretación personalmente significativa y a la vez adecuada al texto. En una conversación final pueden comparar y debatir sus interpretaciones, para ver si coinciden entre sí o deberían desarrollarlas más. Puede existir en el texto una referencia explícita a la visión de la realidad encerrando una visión nueva o matizada de la misma, que requiere que los participantes reajusten la relación con sus esquemas de percepción, que se integre en estos esquemas y obtenga así una visión cambiada de su rea- 
lidad cotidiana. Si bien este enfoque no es necesario para el trabajo con todos los textos literarios, en muchos casos puede ser útil el hacer explícito esta referencia a la realidad.

Debido a la apertura de muchos textos ficcionales a un trasfondo difícil de comprender, a descripciones de conflictos, contradicciones o una simbología, otra fase consistiría en llamar la atención sobre una percepción más cercana al texto y a determinadas referencias, para evitar unas interpretaciones arbitrarias durante el proceso de comprensión. Vincon (2004: 5 $\left.5^{\mathrm{I}-55}\right)$ señala, por tanto, las siguientes categorías básicas en función a las competencias literarias:

I. Reconocer los párrafos importantes y relevantes en los textos;

2. Establecer la capacidad de empatía con las figuras literarias;

3. Comprender la apertura de los textos literarios;

4. Conocer la perspectiva literaria;

5. Reconocer las imágenes lingüísticas, la metafórica, las formas simbólicas, expresiones estilísticas llamativas;

6. Fomentar la comprensión para lo extraño en relación con un contenido innovador e imaginario o con el comportamiento de los protagonistas.

Otros han modernizado la terminología de la siguiente forma con un modelo que incluye las siguientes cuatro fases: la iniciación, la interpretación textual, la relación con la realidad y la contextualización (Saupe, 2OI2: i68). A continuación se ejemplifica cada una de las fases a través de los siguientes ítems:

I. Conexión con el texto: ¿Qué desencadena el texto dentro de mí?

2. Preguntas al texto: ¿Qué pone exactamente?

3. Apropiación: ¿Qué se desprende del texto para mí?

4. Aplicación: ¿Qué se desprende del texto para nosotros?

Para las diferentes fases de la conversación literaria pueden ser útiles las siguientes propuestas (especialmente en clases de lenguas extrajeras):

- Para la conversación inicial: formular las propias experiencias de lectura;

- Presentar oralmente información complementaria si es necesaria;

- Para el debate: encontrar y representar la propia posición;

- Para la argumentación: seleccionar y utilizar la información para un argumento concluyente;

- Preparar un breve resumen/una presentación oral;

- Entrevistar a personajes interesantes en referencia con la obra;

- Crear preguntas para una entrevista. 
Con todas estas propuestas para la conversación literaria buscamos que los participantes hablen a diferentes niveles y combinen la imaginación, el conocimiento del mundo con sus propias experiencias y reflexiones con el objetivo que, según Zabka (2015: I80), consiste en formular unas contribuciones a través de la comprensión exacta del texto que aporten algo nuevo al tema. De esta forma para este propósito deben:

I. Prestar atención a las semejanzas y diferencias de sus interpretaciones con las interpretaciones de los compañeros de clase;

2. Indicar incompatibilidades en su interpretación respecto a los elementos o estructuras del texto;

3. Indicar los elementos del texto que (todavía) pueden ser valiosos para una interpretación más productiva;

4. Llamar la atención sobre contexto que es necesario o de interés para una interpretación más productiva.

Resulta evidente que la conversación literaria, en su mayor apertura posible, no puede prescindir de un reconocimiento exacto de los elementos textuales al ser un requisito previo para una interpretación del texto que es la base de una ulterior y deseada relación con la realidad. Los participantes, por tanto, deben descubrir la visión del mundo sugerida en el texto, para poder aplicarla a su propia realidad de la vida. Y sólo a través de una referencia a la realidad podrán utilizar esta función central implícita de los textos literarios, dado que la comprensión de un texto literario no es únicamente un rendimiento cognitivo. Con estas reflexiones hacemos referencia a la capacidad de adquirir y aplicar ideas que, en recientes trabajos didácticos, se comprenden bajo el concepto de las competencias relacionales de la realidad y ficción o ‘competencia de relación’. En relación con este concepto, Saupe (2OI2: $5^{\mathrm{O}}$ ), afirma lo siguiente:

La comprensión de un texto literario sin su relación con la realidad de la vida es, en última instancia, poco gratificante. Si bien se pueden aportar apreciaciones subjetivas sobre el texto en la interpretación, pero el lector y su relación con la realidad no experimentan ningún cambio (permanente) o un enriquecimiento. El texto puede pasar de largo al lector, en el peor de los casos, a pesar de reconocimiento de estructuras y de la interpretación. Desde el punto de vista didáctico se recomienda separar la interpretación y relación con la realidad; debido a que una interpretación, como un paso antes de la referencia a la realidad, puede contribuir a que el texto literario sea significativo para los estudiantes sin ser utilizado sólo como un desencadenante de asociaciones o para confirmar perspectivas convencionales.

Por las razones aquí mencionadas he comprobado que en el aula son especialmente fructíferos para la conversación literaria aquellos textos literarios que enfrentan al lector con un margen de juego amplío, en otras palabras, que no pueden ser comprendidos 
de la misma manera por todos los lectores. Este juego se da especialmente en narrativas post-modernas donde el grado de apertura y ambigüedad es mayor, y el lector tiene que aceptar una variedad de diferentes motivos en la actuación de un personaje ${ }^{3}$. Abraham (2004: 220) resalta esta función de la literatura como un medio que juega con nuestros conocimientos y seduce el afán de saber. Aludimos con ello especialmente a aquellas novelas en las cuales sus escritores hacen uso de la llamada libertad artística, cuando juegan y modifican detalles históricos, biográficos u otros hechos porque así retan al lector. La lectura y conversación literaria pueden aprovecharse para una animada conversación en el aula, cuando los alumnos se ponen a investigar y buscar información adicional sobre lo que han leído, aportando sus reflexiones sobre nuevos conocimientos del mundo, especialmente en el caso de textos que nos llevan a tiempos históricamente y lugares geográficamente lejanos.

Para determinados textos y grupos de aprendizaje hará falta referirse a un conocimiento más específico del mundo. Esto puede llevar a conectar con un conocimiento de otras obras literarias o artísticas de otro tipo, a la que el texto se refiere intertextualmente, además de un conocimiento de la teoría literaria y de los contextos históricos de la literatura o, el conocimiento sobre la biografía del autor.

\section{Conclusiones y reflexiones}

Formulamos al principio que el objetivo central de la conversación literaria es la comprensión textual, con toda la dificultad que entraña, para usarla en una perspectiva nueva de la realidad. Para ello, esperamos haber demostrado que no se puede renunciar a la conversación en el aula de literatura. Así lo ha expresado Saupe (20I5: I55):

De particular importancia es la conversación literaria pues puede ser vista como el 'método’ para la interpretación. En la conversación los estudiantes pueden contrastar las propias interpretaciones con las interpretaciones de sus compañeros y de este modo confirmar su propia visión y modificarla. Tal conversación se encuentra principalmente en la tradición de los conceptos hermenéuticos de la teoría literaria, que la consideran como una convocatoria imprescindible para la interpretación de textos literarios.

El método de la conversación literaria, como hemos expuesto, busca un diálogo lo más libre posible entre todos los participantes con referencias al texto y las propias experiencias buscando esta interacción entre las contribuciones asociativas y en resonancia al texto, sus elementos y estructuras particulares. El participante ante todo es llamado a entrar en el mundo del texto y a formarse sus imaginaciones internas de forma personal.

\footnotetext{
${ }^{3}$ En el grupo de conversación de alemán ha resultado muy exitosa la lectura de la novela postmoderna 'La medición del mundo’ de Daniel Kehlmann que es una biografía ficcional de Humboldt y Gauß.
} 
Solamente así será capaz de comprender el texto literario que le exige esta implicación subjetiva, encontrar sus propios pensamientos, sentimientos y experiencias en el texto, a la vez que se encuentra con algo nuevo y desconocido. Así aprenderá a interactuar en dos dimensiones, a identificarse y empatizar con los personajes, a asumir otras perspectivas sabiendo al mismo tiempo distanciarse de los personajes. A menudo se crea cierta tensión entre la ficción y la realidad, que debe ser reconocida. La apertura y la ambigüedad del texto literario deben ser aceptadas, sus metáforas y símbolos de significado reconocidas y entendidas. Sucede cuando se producen experiencias estéticas intensas en una profundización de la comprensión, que abarca fases y procesos, que no son nada fáciles de enseñar.

La conversación literaria, por tanto, corresponde a una forma especial de tratar la literatura y la comprensión literaria, es un procedimiento didáctico indispensable y no sólo un método entre otros, debido a que sobre todo en la conversación el proceso de la comprensión se acerca del mejor modo a la 'polifonía' de la obra poética. Para el trabajo con textos literarios, la conversación indudablemente es incluso el método principal, ya que podemos considerarlo ‘en gran medida’ como el camino más válido para la interpretación de textos literarios que, sin embargo, como anteriormente hemos argumentado, requiere que el docente asuma un rol de enseñante y participante a la vez, que converse con los alumnos sobre la literatura y sus posibilidades de significado (Härle y Steinbrenner, 2OI4: 2O). Esta concepción de la conversación va enfocada a una forma de comunicación que permite a todos una participación lo más honesta, abierta y cercana posible. Con todo lo dicho anteriormente, saber conversar es un arte como cualquier otro que merece la pena ser promovido como una forma de aprendizaje, tanto entre los participantes/ alumnos mismos, como entre estudiantes y enseñantes juntos, para que se convierta en la actividad principal y forma social de la enseñanza. 


\section{Referencias bibliográficas}

-Abraham, U. (2004). Lernen- Lesen- Wissen, Fächerverbindender Literaturunterricht und Lesekompetenz. En G. Härle y B. Rank (eds.). Wege zum Lesen und zur Literatur, (pp. 2I7-222). Baltmannsweiler: Schneider.

-Álvarez, C. y González, L. y Larrinaga, A. (20I2). Estilos de aprendizaje: investigaciones y experiencias: Una apuesta de centro educativo que favorece la inclusión. Obtenido el i6 de agosto de 2017 desde https://dialnet.unirioja.es/servlet/articulo? codigo $=4644436$

- Bittner, S. (2006). Das Unterrichtsgespräch. Bad Heilbrunn: Julius Klinhardt Verlag.

- Härle, G. y Rank, B. (eds.). (2004). Wege zum Lesen und zur Literatur. Baltmannsweiler: Schneider.

- Härle, G. (2004). Literarische Gespräche im Unterricht. En G. Härle y B. Rank (eds.). Wege zum Lesen und zur Literatur, (pp. I-5). Baltmannsweiler: Schneider.

- Härle, G. (2OII). Grundlagen des Literarischen Unterrichtsgesprächs. En M. Steinbrenner y J. Mayer y B. Rank (eds.). Seit ein Gespräch wir sind und hören voneinander, (pp. 2965). Baltmannsweiler: Schneider Verlag.

- Härle, G. y Steinbrenner, M. (eds.). (20I4). Kein endgültiges Wort. Baltmannsweiler: Schneider.

- Jürgens, H.-J. (2OI4). Literarisches Lernen mit Kinderliteratur als Beitrag zur ästhetischen Bildung im Deutschunterricht der Primarstufe. Libri \&Liberi, 3 (I), (pp. 75-94).

- Martín, Ma I. y Jiménez, A. (20I3). Las tertulias literarias dialógicas, un desafío para la creatividad y la convivencia. Revista Creatividady Sociedad, nº 2I, (pp. I-2I).

- Nickel-Bacon, I. (2OII). Authentizität in der literarischen Kommunikation: Anthropologische, poetologische und didaktische Aspekte. En M. Steinbrenner y J. Mayer y B. Rank (eds.). Seit ein Gespräch wir sind. Das Heidelberger Modell des Literarischen Unterrichtsgesprächs in Theorie und Praxis, (pp. II7-I38). Baltmannsweiler: Schneider.

- Pulido, C y Zepa, B. (2OIO). La interpretación interactiva de los textos a través de las tertulias literarias dialógicas. Revista Signos, 43 (2), (pp. 295-309).

- Saupe, A. y Leubner, M. y Richter, M. (eds.). (20I2). Literaturdidaktik. Berlin: Akademie Verlag. 
- Spinner, K. H. (2004). Literarisches Verstehen und die Grenzen von PISA. En G. Härle y B. Rank (eds.). Wege zum Lesen und zur Literatur, (pp. I69-I73). Baltmannsweiler: Schneider.

- Steinbrenner, M. y Wiprächtiger-Geppert, M. (20I0). Verstehen und Nicht-Verstehen im Gespräch. Obtenido el 24 de octubre de 2016 desde http://leseforum.ch/myUploadData/ files/2OIO_3_steinbrenner_wipraechtiger.pdf

- Steinbrenner, M. y Mayer, J. y Rank, B. (eds.). (2OII). Seit ein Gespräch wir sind und hören voneinander. Baltmannsweiler: Schneider Verlag.

- Valls, R. y Soler, M. y Flecha R. (2008). Lectura dialógica: interaccion es que mejoran y aceleran la lectura. Revista Iberoamericana de Educación, $\mathrm{n}^{\circ}{ }_{4} 6$. Obtenido el i6 de agosto de 2017 desde http://rieoei.org/rie46aO4.htm

- Vincon, I. (2004). Diskutieren und Argumentieren beim Umgang mit literarischen Texten. En G. Härle y B. Rank (eds.). Wege zum Lesen und zur Literatur, (pp. 5-55). Baltmannsweiler: Schneider.

-Werner, J. (20I4). Schulisches Interpretieren als Deutungsspiel. En G. Härle y M. Steinbrenner (eds.). Kein endgültiges Wort, (pp.ı9I-2I8). Baltmannsweiler: Schneider.

-Zabka, T. (20I5). Konversation oder Interpretation? Überlegungen zum Gespräch im Literaturunterricht. Leseräume, 2, (pp. I69-187). 